\title{
Does Androgen Hormone Influences Sexual Orientation?
}

\author{
By: Taufiq RN
}

Now days lesbian, gay, bisexual, and transgender are abbreviated as LGBT is the most popular word and being sensible in the world, especially in Indonesia. Based on human right principles, any person in the world including in Indonesia is free to express their gender identity and sexual orientation, even the same sex marriage, freely from unlawful discrimination and violations (Office of Personnel Management, 2015; Yogyakarta Principles, 2006). However, because of the culture and religion differences backgrounds, Indonesians have given this issue various responses. In general, Indonesian public opinion on LGBT are split into two different groups, one minority group is proponent to present of LGBT and any things related to it, and another majority groups are opponent. Objective of this editorial is to discuss how sexual orientation develop from prenatal until emerging of clinical manifestation in adulthood, by no mean to support either group. Otherwise, to give more insight about how male and female get their appropriate sexual orientations and why some of them get inappropriate sexual orientations.

Sexual orientation means one's emotional or physical attraction to the same and or opposite sex, in another word sexual orientation is reflective of individual choice to their sexual partner (Balthazart, 2011). Virtually, majority of people (90-97\%) are sexually attracted to individuals of the opposite sex, and known as heterosexual. However, in population there is about $3-10 \%$ of individuals are emotional or physical attracted to individuals of their own sex, and known as homosexual (Balthazart, 2011). According to Kinsay, classification of sexual attraction could be divided into seven distinct catagories ranging from completely heterosexual to completely homosexual and bisexual is in between (Kinsey, 1948; Balthazart J, 2011). The concern of this discussion is try to explain the mechanism that determines how sexual orientation occurs, is there any hormonal contribution especially androgen? Because sexual orientation is tightly related to the normal process of reproductive development in mammals and human that extremly influnced by hormone. Therefore, this discussion will be focused on the basic mechanism of reproductive development in human and how hormones influences reproductive and psychosexual development. This explanation will emphasize on human, even though the important information obtained from animal model studies will be included to discuss the relevance of the finding to individual sexual orientation disorder; especially it's related to hormonal perspective.

Development of reproductive system in human begin at 4 or 5 weeks of gestation until puberty that is characterized with complete development of secondary sexual characteristics and fertility. The reproductive development process is very dynamic, a multitude factors including genes, protein (enzyme), endocrine, steroid hormone, and signaling factors contributing to this process (Brennan J, Capel B, 2004). There are three basic processes of normal mechanism of reproductive development consisting of: i. sex determination and differentiation; ii, development of the hypothalamicgonadotrophic axis in the fetus; and iii, function of the hypothalamic-pituitary-gonadal (HPG) axis in infancy and childhood (Brennan J, Capel B, 2004). This editorial will be focused on sex determination and differentiation, and in certain extent psychosexual development. Basically sexual determination and differentiation consist of three major components: i. Chromosomal sex (X or Y chromosome); ii. Gonadal sex (ovary or testis); iii. Anatomic sex (male and female internal and external genitalia) (Achermann JC, Hughes, 2011). However none of these processes absolutely define person's sex, considering that psychosexual or brain sex is influenced by several biological factors derived from environment or social. Understanding these processes can be helpful construct investigation and diagnosis of sexual development disorder.

Sex determination is the process in which the indifferent gonad develops to either a testis or an ovary. Mean while sex differentiation is the process whereby Wolffian or Mullerian duct develops into final shape of internal reproductive organ, for instance Wolffian duct developes to seminal vesicles, vas deferent, epididymides in male, whereas Mullerian duct develops to uterus, fallopian tubes, and the upper one third of the 
vagina in female. Sex determination is fully regulated by sex determining region of $Y$ and so called SRY. Furthermore SRY stimulates Sertoli cells to produce Anti Mullerian Hormone and subsequently drive mullerian tube degeneration. Accordingly mutation of SRY gen in human with XY give rise dysgenesis completely, otherwise in transgenic XX mice expressing SRY displayed male phenotype, had testes, and male mating behavior. In addition to SRY gen, androgen is needed for development of external genitalia. Androgen is a hormone that account for androgenization of external genitalia including penis and scrotum and decent of the testes from urogenital ridge to the final position in scrotum (Achermann JC, Hughes, 2011). Unlike in male, estrogenization of external genitalia in female including breast enlargement, ovary and uterine development are quiescent until the time of puberty and so called default process or SRY negative developmental pathway. However, recent study indicated that female sex differentiation also involve RSPO1, DAX-1, and WNT4 gen that serve as testes development antagonist (DiNapoli, Capel, 2008; Achermann JC, Hughes, 2011).

In psychosexual development, high level of androgen promote male typical neural and behavioral characteristic, whereas low level of androgen stimulate female typical characteristics. Similarly, study of mice in which SRY was deleted (XYSRY-) and transgeniccally express (XXSRY) indicated certain neuroanatomic different between $\mathrm{XY}$ and $\mathrm{XX}$ mice independent of hormonal status (Arnold AP, Chen X, 2009). Based on these data the development of psychosexual can be regulated by hormonal and genetic. However several studies showed that androgen effects have been displayed more clearly in reproductive behaviors. Various studies indicated that female rodents and nonhuman primates that are administrated testosterone during early gestation show increased male typical behaviors (mounting) and decreased female typical behaviors (lordosis) in adulthood. In contrary male denied testosterone in early gestation period display decreased mounting and increased lordosis as adult (Hines, 2004). Similarly, data obtained from animal research showed that when the male fetus of the medial region of preoptic anterior hypothalamus (mPOA) in 8-12 weeks of gestation was absent or minimally exposured to testosterone, the size and number of neuron cells in mPOA become significantly reduced (smaller)
Does Androgen Hormone Influences Sexual Orientation?... compared with optimum exposure to testosterone (larger). Implication of these circumstances were homosexual and heterosexual respectively (Balthazart J, 2011). In another words small size of mPOA is tightly addressed to homosexuality, whereas larger size of mPOA addressed to heterosexuality, and unfortunately, this occurrence is irreversible. On the other hand, androgenization could be occurred in female fetus result from exposure of androgen. Therefore when a uterus exists the local androgen is not sufficient to stabilize wolfian duct structures because the androgen usually resulted from adrenal cortex or phyto-androgen consumptive (Achermann JC, Hughes, 2011). However, androgenization of female fetus during gestation capable to influence psychosexual development. Data from congenital adrenal hyperplasia (CAH) study indicated that girls with $\mathrm{CAH}$ who suffer from severe genetic mutation and marked by evident genital androgenization likely to play more with boys toys, and associated with sexual orientation until adulthood (Hines, 2004). Another study in guinea pig reported by Phonix and Young and coworkers demonstrated that castration of male guinea pig immediately after birth induce female courtship phenotype (non masculinized), meanwhile testosterone injection into female fetus of guinea pig early after birth induce male courtship phenotype (masculinized female). Based on this data, in the hormonal view point certain period (8-12 weeks) of gestation and in early life of infancy have pivotal role to determine whether an organism may lead to become either homosexual or heterosexual. However, further research is needed, since there are still a lot of pros and cons.

\section{REFERENCES:}

Achermann JC, Hughes IA. Disorders of Sex Development. In: Melmed S, Polonsky KS, Larsen PR, Kronenberg HM. Williams textbook of endocrinology. 12 $2^{\text {th }}$ ed 2011; P: 869-1016.

Arnold AP, Chen X. What does the "four core genotypes" mouse model tell us about sex differences in the brain and other tissues? Front Neuroendocrinol. 2009;30:1-9.

Balthazart J. Minireview: Hormones and Human Sexual Orientation. Endocrinology 2011; 152: 2937-2947, 2011). 


\section{Taufiqurrachman}

Brennan J, Capel B. One tissue, two fates: molecular genetic events that underlie testis versus ovary development. Nat Rev Genet. 2004;5:509-521.

DiNapoli L, Capel B. SRY and the standoff in sex determination. Mol Endocrinol. 2008;22:1-9.

Hines M, Brook C, Conway GS. Androgen and psychosexual development:core gender identity, sexual orientation and recalled childhood gender role behavior in women and men with congenital adrenal hyperplasia (CAH). J Sex Res. 2004;41:7581.

Kinsey AC, Pomeroy WR, Martin CE. Sexual behavior in the human male. Philadelphia: W.B. Saunders Co. 1948 http://jurnal.unissula.ac.id/index.php/sainsmedika

United state Office of Personnel Management, the Equal Employment Opportunity Commission, the Office of Special Counsel, and the Merit Systems Protection Board. Addressing Sexual Orientation and Gender Identity Discrimination in Federal Civilian Employment A Guide to Employment Rights, Protections, and Responsibilities; Rev June 2015.

Yogyakarta Principles. The Application of International Human Right Law in Relation to Sexual Orientation and Gender Identity, 2006. 